\title{
Mediación desde el diseño gráfico social para la integración de refugiados emprendedores en Ecuador ${ }^{1}$
}

Nuria Rey Somoza ${ }^{2}$ - Melba Cristina Marmolejo Cueva ${ }^{3}$ - Rafael Luque de Dios ${ }^{4}$ Pontificia Universidad Católica de Ecuador Sede Esmeraldas

\author{
RECIBIDO: 18.02.2018 / ACEPTADO: 24.03.2018
}

\section{Resumen}

Desde el diseño social, el diseñador es capaz de establecer procesos comunitarios para crear productos y situaciones que mejoren las condiciones de vida. En este artículo se incluyen los métodos de trabajo interdisciplinario entre diseñadores gráficos, técnicos de atención al refugiado y emprendedores de Esmeraldas (Ecuador), concluyendo que la participación desde el diseño aporta significativamente en la integración al nuevo contexto del emprendedor refugiado.

Palabras clave: diseño social, integración, emprendimiento, refugiados, Ecuador

\section{Mediation from the social graphic design for the integration of entrepreneur refugees in Ecuador}

\begin{abstract}
The study analyses the process of realization and standardization in the creation of a modern product as it is the book, the typographic design inherent in the product itself, as well as the gestation of the first globalized product. This study is takes to out doing a tour historic that us allows contrast differences fundamental among them codices of them different cultures and the book in the century XVI, as well as the history of the editorial and typographic design.
\end{abstract}

Keywords: social design, integration, entrepeneur, refugees, Ecuador

\footnotetext{
1 Los autores agradecen el trabajo y colaboración del equipo técnico del proyecto PUCESE-ACNUR, en especial a las técnicas de seguimiento empresarial Ana Gómez y Diana Saquisari; así como a la Oficina de ACNUR Esmeraldas y en concreto a Óscar Sánchez, Responsable Nacional de Medios de Vida ACNUR Ecuador, hasta el momento de redacción del artículo.

2 Máster en Educación Artística en Instituciones Sociales y Culturales, Universidad Complutense de Madrid (España), cursando desde el año 2016 el Programa de Doctorado en la misma institución. Ocupa el cargo de docente investigadora en la Escuela de Diseño Gráfico de la Pontificia Universidad Católica de Ecuador Sede Esmeraldas. Es coordinadora de investigación en la Escuela de Diseño Gráfico. Contacto: nuria.rey@pucese.edu.ec

3 Máster en Diseño de experiencia de usuario por la Universidad Internacional de la Rioja (España) y Máster en Tecnologías para la gestión y práctica docente por la Pontificia Universidad Católica de Ecuador Sede Esmeraldas. Ocupa el cargo de docente investigadora en la Escuela de Diseño Gráfico de la Pontificia Universidad Católica de Ecuador Sede Esmeraldas desde el año 2007. Participa en varios proyectos de investigación de manera transversal desde las disciplinas del diseño gráfico, las tecnologías y la cultura. Contacto: melba.marmolejo@pucese.edu.ec

4 Máster en Cultura de paz, conflictos, educación y derechos humanos por la Universidad de Córdoba (España). Coordinador del proyecto ACNUR-PUCESE en la Pontificia Universidad Católica de Ecuador Sede Esmeraldas hasta julio de 2017 y docente en la Escuela de Educación. Dirige la Fundación Lunita Lunera en Esmeraldas y es coordinador de zona fronteriza Ecuador-Colombia en Lago Agrio con UNICEF. Contacto: rafael.luque@pucese.edu.ec
} 


\section{Introducción}

El desplazamiento forzado de personas es una problemática que afecta el modo de vida y repercute en las zonas de acogida. Las personas movilizadas debido a un temor justificado por sus vidas fuera de su país son categorizadas como refugiadas, normalmente por razones de violencia o crisis económica y/o social. Para asegurar su acceso a derechos básicos, varias organizaciones colaboran con ellas sobre el propósito de mejorar las condiciones de vida fuera de su lugar de origen. El Alto Comisionado de las Naciones Unidas para los Refugiados (ACNUR) es la entidad, reglamentada en la Declaración Universal de Derechos Humanos, que se encarga de proteger a refugiados y desplazados en todo el mundo.

Según un informe elaborado por ACNUR en 2014, existe un total de 5.996 personas colombianas solicitantes de asilo en Esmeraldas (Ecuador), al ser país fronterizo. Desde 2012, esta institución humanitaria, en coordinación con las unidades de Género y Emprendimiento de la Pontificia Universidad Católica del Ecuador Sede Esmeraldas (PUCESE), efectúa un conjunto de actividades dentro del proceso de generación de negocios. Entre éstas, destaca el de diseño de identidad visual aplicado a la imagen para productos/ servicios emprendidos por población refugiada asentada en la zona. Estas relaciones se establecen desde el Proyecto de Fortalecimiento de Imagen para el Emprendimiento, siendo uno de los pilares para el proceso de vinculación de los estudiantes de la carrera de Diseño Gráfico de la institución universitaria mencionada.

El cambio de enfoque de un diseño orientado hacia la generación de soluciones comunicacionales con fines sociales se conoce como diseño social. Este proyecto sigue ese planteamiento, por lo que se considera un caso práctico de diseño social que parte de la institución con el propósito principal de asistir desde esta área de conocimiento y producción a la mejora de calidad de vida de la población afectada. Los objetivos de este estudio son extraer las valoraciones de la colaboración entre estudiantes de diseño gráfico y personas refugiadas emprendedoras en el contexto mencionado, así como reflexionar en torno a los beneficios y obstáculos de estas relaciones desde el diseño social. La fundamentación del proyecto se establece a partir de su pertinencia, relevancia local, su valor teórico, así como desde sus utilidades prácticas y metodológicas. Su conveniencia radica en la necesidad de entender al profesional del diseño como un agente para la transformación social, legitimando sus capacidades y aportes a nivel local. En este caso concreto, el equipo de diseño, desde la organización universitaria, entiende que puede contribuir con sus habilidades para la visibilización y asentamiento del colectivo refugiado de la región. Su valor teórico-práctico se fundamenta en el mismo fenómeno, y es que no existe ningún antecedente a nivel local sobre el trabajo con personas refugiadas desde los procesos de integración poniendo en valor el potencial del diseño como ámbito de producción creativa y de encuentro. Además, la utilidad metodológica del proyecto se constata al configurarse como un puente entre otras experiencias similares y posibles vías futuras de intervención.

\section{El diseño en la intervención social: concepciones y proyectos antecedentes}

Aunque el diseño gráfico como disciplina se originó para responder a necesidades comunicativas y diferenciadoras de productos generados masivamente en la era industrial, la realidad social demanda otra forma de participación a través de proyectos sociales, culturales y económicos de impacto. Como señala Costa (2014), el profesional del diseño y la comunicación debe tener presente la utilidad de su profesión en el plano social. 
El impacto del diseño gráfico inserto en la cultura-contexto ha sido motivo de reflexión y debate desde hace algunos años (Melenje, 2014). Para conseguir una transformación social a través del diseño, el profesional debe integrarse e identificarse con el entorno, y de esta manera, ser capaz de construir discursos visuales comunicativos en coherencia, transformándose en interlocutor cultural desde la imagen. Por ello, su implicación trasciende del producto al priorizar otros aspectos, como los significados que construye el material diseñado y la aceptación de éstos por parte de la comunidad a la que se dirige (Melenje, 2014).

El cambio de enfoque de un diseño gráfico hacia un diseño con proyección a mejorar condiciones de vida obedece al cambio de paradigma dentro de una sociedad cada vez más global e informada, cuyos intereses apuntan a la equidad de diferentes grupos. El hecho de involucrar a la comunidad con características de vulnerabilidad en el proceso de gestión comunicacional del diseño provoca que perciban su participación como una acción encaminada al beneficio de todos, buscando la comunicación efectiva del fenómeno. Sin embargo, como consideran Bernard y Morales (2012), el desarrollo del diseño en el campo social no ha sido explorado lo suficiente.

De la misma manera que Bonsiepe (1999) recuerda que no todo es diseño, no todas las intervenciones desde el ámbito social configurarán la acción en diseño social. La dimensión del diseño social, o del diseñador como agente social, puede conformarse a partir de los principios ya establecidos del diseño gráfico, con el fin de no invadir otras áreas de conocimiento sino de contribuir desde un carácter interdisciplinar, tal como señala Nowotny (2006) al referirse al proceso de investigación: conviviendo distintas perspectivas para ofrecer respuestas a un problema común y para la generación de conocimiento colectivo. De esta manera, se deberá actuar desde el ámbito definido del diseñador, trabajando desde la gráfica y la imagen como medios de comunicación visual en favor de un objetivo localizado. Como apunta Loewy (2002), el diseño se basa en la intención de cambiar, pudiendo ser esta definición complementada por las indicaciones de Ledesma (2009) cuando expone que el diseño gráfico opera desde la cultura, afectos y subjetividad del ser humano, convirtiéndose en una disciplina capaz de articular saberes y modos de producir diversos. También en este sentido, Brown (2008) establece algunas de las características que predominan en el perfil de un diseñador, encontrándose entre estas la empatía (imaginar el mundo desde varias perspectivas) y la colaboración (huyendo de la idea del genio solitario).

La capacidad de poder integrar las aportaciones desde el diseño es, como explica Aicher (1994, p.164) una consecuencia de trabajar en un sector "indómito de la sociedad", teniendo cierto margen a la hora de experimentar desde la capacidad creativa en diversos ámbitos. Papanek $(1983 ; 1971)$ introduce ya algunas concepciones sobre la necesidad de generar ideas y productos de diseño según la necesidad real de los usuarios y no desde el imaginario del diseñador, invitando al diseño participativo o participado donde el usuario final es un aliado involucrado en el proceso.

De la misma manera, el desarrollo de prácticas desde el diseño social está ligado al recorrido de la politización del diseño, en el sentido de ponerse al servicio de las demandas, conflictos y cambios sociales. Pelta (2002) expone esta historia del diseño como activismo o diseño de protesta, que comprende diferentes cuestionamientos según el periodo histórico. Ejemplos de este diseño activista son, desde Pugin o Morris al buscar una producción humanizada para la transformación del sistema, pasando por el activismo presente 
en el periodo de vanguardias y por la Bauhaus, hasta las corrientes de respuesta gráfica a conflictos sociales como las guerras, el feminismo, la lucha por los derechos humanos y medioambientales, hasta desembocar en fenómenos recientes como el "Occupy Design". El denominador común de estas iniciativas o posicionamientos en el mundo del diseño es el de orientar la creación hacia áreas o causas humanitarias, a favor del cambio de imaginario para la transformación social.

La inclusión del diseño social en la planificación de las intervenciones se puede contemplar desde diferentes concepciones (Del Valle, 2014). La primera de ellas sería la intervención de carácter propagandístico, enfocado en visibilizar algún tipo de conciencia social. La segunda consistiría en generar productos tendentes a incluir algún colectivo vulnerable. La tercera concepción se enfocaría en intervenir desde el diseño para ofrecer servicios profesionales a personas que no tengan ese acceso. Una cuarta concepción sería la de colaborar desde el diseño en comunidad. Otra manera de entender el diseño social sería con la intención de intervenir en el proceso de construcción de identidades y en el reconocimiento de territorios con el fin de empoderar a un colectivo concreto. La última concepción sería la de aportar desde el diseño a favor del desarrollo económico y humano a nivel estatal para colaborar con un estado del bienestar.

Gómez (2014) asevera que las problemáticas sociales son fenómenos que en el transcurso del tiempo se transforman a medida que la sociedad cambia. Éstas son originadas por diversos factores, que van desde la crisis económica hasta el calentamiento global, abriendo posibilidades multidisciplinares para construir iniciativas mediadoras. El diseño está en la intersección entre lo cotidiano, lo tecnológico y lo económico, siendo uno de los fundamentos para el crecimiento de la disciplina a nivel latinoamericano (Gómez, 2014). Esta perspectiva determina que la labor del diseñador es visualizar y materializar la noción de futuro a través de la integración del conocimiento y las capacidades de los involucrados, produciendo cohesión social, rescate de valores, autoestima y crecimiento común.

La concepción de un profesional del diseño consiente de su rol en la sociedad no es algo nuevo. Desde la academia a nivel superior, se presentan casos de instituciones educativas con metodologías de integración social que sirven como antecedentes directos en este estudio, a falta de antecedentes académicos sobre el trabajo de diseño gráfico con colectivos refugiados. Uno de ellos es el programa metodológico de Trabajo Real Aplicado a Empresas (TRAE) del Instituto Touluse-Lautrec, cuyo planteamiento es relacionar a estudiantes con organizaciones que buscan mejorar la sociedad en el contexto peruano, tal como expone Moreno (2014). Este método permite un acercamiento del diseñador con la realidad para generar sensibilización colectiva y mayor nivel de compromiso, además de permitir poner en marcha proyectos multidisciplinares para los estudiantes. Entre los diversos ámbitos de intervención se menciona, por ejemplo, la campaña de concientización para combatir el racismo, el desarrollo social en organizaciones como "Ashoka internacional" para emprendedores sociales, o la ONG "Inventar" que trabaja con emprendedores sociales y culturales. Concluyen estas experiencias que los diseñadores conscientes de su realidad se convierten en profesionales identificados con la comunidad, y desde sus competencias son capaces de crear cambios significativos.

A nivel local, en Esmeraldas no existen antecedentes de procesos interdisciplinarios que cuenten con profesionales del diseño actuando desde la perspectiva social, aunque sí tiene varias generaciones de diseñadores formados en la universidad que han convivido con la problemática de la migración forzada. Sin embargo, desde el contexto ecuatoriano, y para dibujar una territorialidad del diseño social a nivel nacional, sí 
existen algunos estudios y proyectos de interés. Algunos están disponibles como trabajos o tesinas de grado, como el realizado por Jaramillo (2011) aplicando la idea de diseño social desde la arquitectura en un caso de la ciudad de Loja, o el desarrollado por Cáceres (2015) al introducir el proceso de creación de marca e identidad visual para la mejora de las condiciones ambientales en entorno hospitalario. Cabe señalar también el cruce que se establece entre los procesos de diseño y la visibilización de las diferentes etnias o nacionalidades de Ecuador a partir de proyectos que fomentan la distribución de productos de las comunidades autóctonas. Es el caso del proyecto Atelier Avanzar, que trabaja desde la responsabilidad social con procesos comunitarios de diseño textil. Como último ejemplo, ha destacado en los últimos años el colectivo ecuatoriano Diseñadores Con Corazón, que en el año 2016 hizo un llamamiento internacional a la producción de carteles desde el diseño gráfico en apoyo a la sociedad que sufrió en su zona costera un fuerte terremoto, causando graves daños humanos y materiales. La recopilación de carteles se materializó tanto en redes sociales como en una publicación editorial.

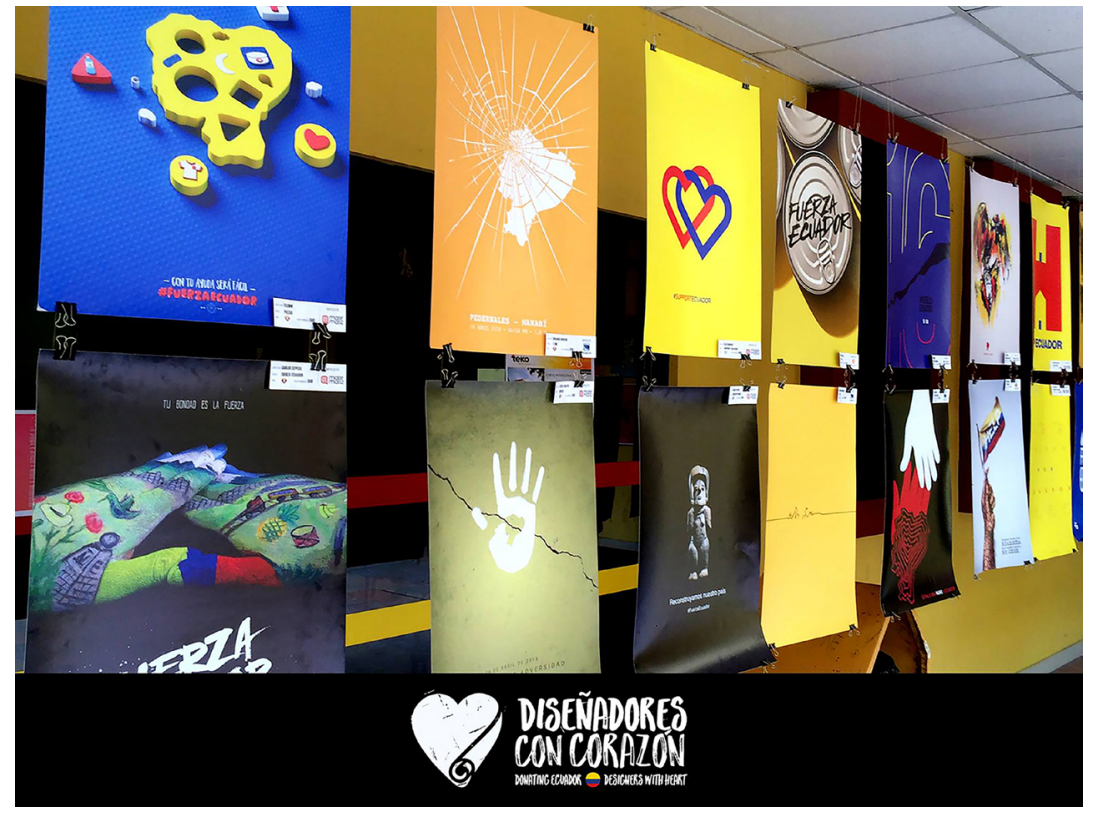

Fig. 1. Exposición de carteles solidarios en la Universidad San Gregorio de Portoviejo (Ecuador). Fotografía de Diseñadores Con Corazón, alojada en la página de Facebook del colectivo en agosto de 2016

\section{Metodología: proceso de investigación y de intervención con la población}

La investigación se expone desde un enfoque exploratorio mixto, por tratarse de un fenómeno poco estudiado a nivel global, con nulo antecedente nacional y local, de modo que constituye un punto de partida para nuevas iniciativas. Encierra un carácter ex post-facto, donde "los hechos [...] ya ocurrieron" (Hernández, Fernández \& Baptista, 2014, p.198), ya que los datos pertenecen a procesos de seguimiento durante el año 2016. Desde el punto de vista del diseño de investigación, el proyecto se aborda desde un carácter no experimental, priorizando el trabajo de campo y el proceso experiencial. No aplica, en este caso, objeto de estudio, sino obtención de datos a partir de las valoraciones de la población. Por otro lado, el carácter mixto se da al recoger en primer lugar la relación de variables (ítems Reacción, Aprendizaje, Transferencia e Impacto) de manera cualitativa sobre las jornadas de capacitación en identidad visual para micro-emprendimientos, y 
por último una fase de análisis cuantitativo a partir de la encuesta que mide la variable Satisfacción general de la persona emprendedora. En todo caso, estas variables se refieren a la evaluación de impacto para las personas, teniendo como posibles vías futuras la estimación de impacto en la sociedad y en las empresas o emprendimientos a nivel económico 5 .

La muestra de estudio corresponde a un total de 26 personas, pertenecientes al colectivo de refugiados del proyecto ACNUR, Género y Emprendimiento de la PUCESE, asentadas en la provincia ecuatoriana de Esmeraldas. Esta cifra proviene del número de personas refugiadas que participaron en el proceso de desarrollo de aplicación de soluciones gráficas a sus micro-empresas. A diferencia de los "desplazados internos", que se describe como el grupo de personas obligadas a abandonar su lugar de residencia sin cruzar fronteras por acciones que vulneran sus derechos humanos (Mendia, s.f.), la persona refugiada se precisa como el individuo que es perseguido por pertenecer a un determinado grupo social, etnia, religión, nacionalidad o postura política, siendo movilizadas de manera forzosa fuera de su país de origen (ACNUR, 2016). Se caracterizan por ser personas movilizadas desde Colombia por problemas derivados de la violencia ${ }^{6}$, de mediana edad, que llegan a la localidad de Esmeraldas sin documentación ni recursos y por eso recurren a la ayuda de asociaciones como ACNUR. Generalmente, sus emprendimientos tienen un nivel de avance y estabilidad bajo, rozando en algunos casos el empleo informal. Estos micro-negocios suponen la subsistencia en el nuevo contexto, del que depende el propio emprendedor y sus familiares. El rol que juega la población refugiada dentro del proceso de diseño y comunicación de sus emprendimientos es fundamental porque es quién mejor conoce los atributos y características a ser difundidos, por lo tanto, su implicación como gestor del mensaje es imprescindible para un proceso de integración comunitario.
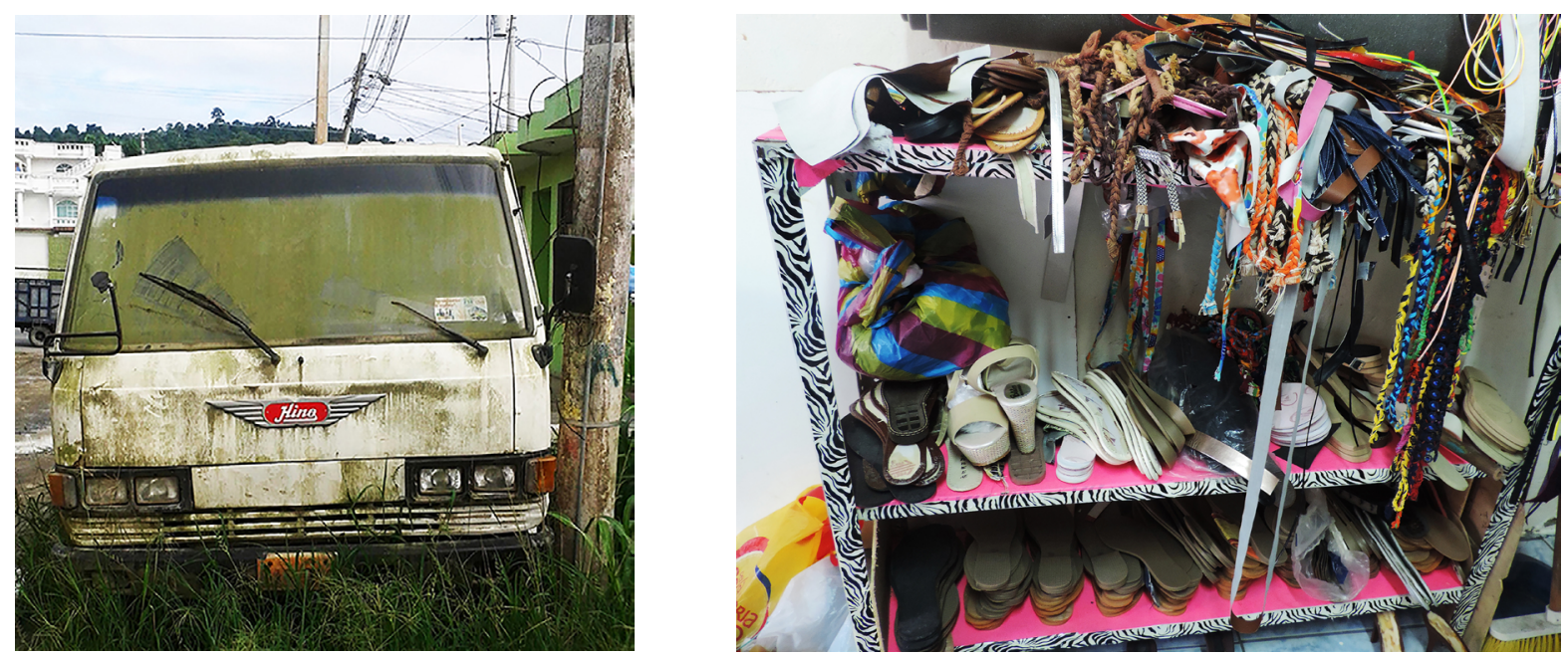

Fig. 2 y 3. Entorno y espacio de trabajo de emprendimientos de calzado. Fotografías por: Nuria Rey (izquierda) y Alex Quinde (derecha).

5 Propuesta de evaluación apoyada en la Guía para la evaluación de impacto de la formación profesional redactada por la Oficina Internacional del Trabajo CINTERFOR <http://guia.oitcinterfor.org/conceptualizacion/que-se-entiende-evaluacion-impacto> (15.04.2018)

6 Debido a esta situación de conflicto, existen normativas en torno al derecho de imagen de no documentar a estas personas ni a sus familiares, bajo parámetros para efectuar su protección como solicitante de refugio. Por ello, no existe documentación gráfica de este tipo en este artículo. 
Los datos del estudio se han obtenido a partir de herramientas que sirvieron para evaluar las sesiones y procesos para poder llevar la disciplina del diseño gráfico al campo de la integración social. En concreto, las herramientas de investigación-evaluación han sido la observación participante, como técnica para llevar procedimientos conjuntos entre el colectivo refugiado junto a los diseñadores, y el cuestionario, aplicado a personas refugiadas implicadas en el proyecto. La observación participante se emplea como instrumento en el trabajo de campo, reafirmando la necesidad de involucrarse en los procesos de un modo directo con la muestra y entendiendo esta herramienta "no como una técnica sino como un modo participativo de detectar contextos" (Guber, 2013, p.88). Ésta es acompañada de una ficha de observación que recoge información acerca de cuatro ítems según el modelo de los niveles de Kirkpatrick, los cuales son:

- Reacción: correspondiente con las expectativas de los participantes.

- Aprendizaje: refiriéndose al incremento del conocimiento y análisis de contenidos.

- Transferencia: indicando el grado de mejora o aceptación de los contenidos.

- Impacto: referido al efecto en el entorno.

Esta información, según las recomendaciones del Manual para educadores de Naciones Unidas (Equitas, 2010), permite evaluar capacitaciones en el contexto de los Derechos Humanos.

El cuestionario, de tipo cerrado, es el instrumento de obtención de datos cuantitativos referentes al nivel de satisfacción de la persona refugiada sobre la importancia de la identidad gráfica para el desarrollo de su emprendimiento. Consiste en un documento con valoraciones en una escala de cinco niveles, de "Excelente" a "Deficiente", siendo un instrumento validado por la institución universitaria a la que se pertenece.

Para afrontar la intervención de diseñadores en el proceso de apoyo al refugiado y su micro-negocio, se consideraron las fases de trabajo de las diferentes organizaciones con las que se colabora. El trabajo de ACNUR, en su programa de Medios de Vida, divide el procedimiento en tres momentos o fases:

- Fase de Provisión, en la que se descubren las necesidades básicas de la persona refugiada.

- Fase de Protección, en la que se concede apoyo al emprendimiento de la persona refugiada.

- Fase de Promoción, que consiste en el momento de mayor inserción desde la llegada al nuevo país, pudiendo normalizar su situación en varios niveles.

La acción del diseñador social se enmarca en el tercer nivel, en la Fase de Promoción, relacionada con la etapa de integración, dotando al emprendimiento de la persona refugiada de una identidad visual propia dentro de las estéticas y características formales de la región de acogida.

El trabajo se ha desarrollado desde la interdisciplinaridad, esto es, poniendo en común los conocimientos y capacidades de profesionales de diferentes áreas para alcanzar la meta común de apoyar y acompañar a la persona refugiada en su proceso de integración. Las áreas colaboradoras son tres, que se han definido como contextos interrelacionados en la práctica. En primer lugar, la universidad como institución educativa con intención de colaborar en la transformación de la localidad, concretando la acción desde la Escuela de Diseño Gráfico (docentes, estudiantes, coordinación) El segundo contexto sería el equipo de la misma institución que trabaja asociado con ACNUR, integrado por los técnicos y técnicas para el desarrollo de Medios de Vida, la coordinación de la universidad y la de la asociación humanitaria. Por último, el tercer contexto es el colectivo 
de refugiados, dispersos según sus asentamientos o domicilios en la región de Esmeraldas, con algunas de las características ya señaladas anteriormente.

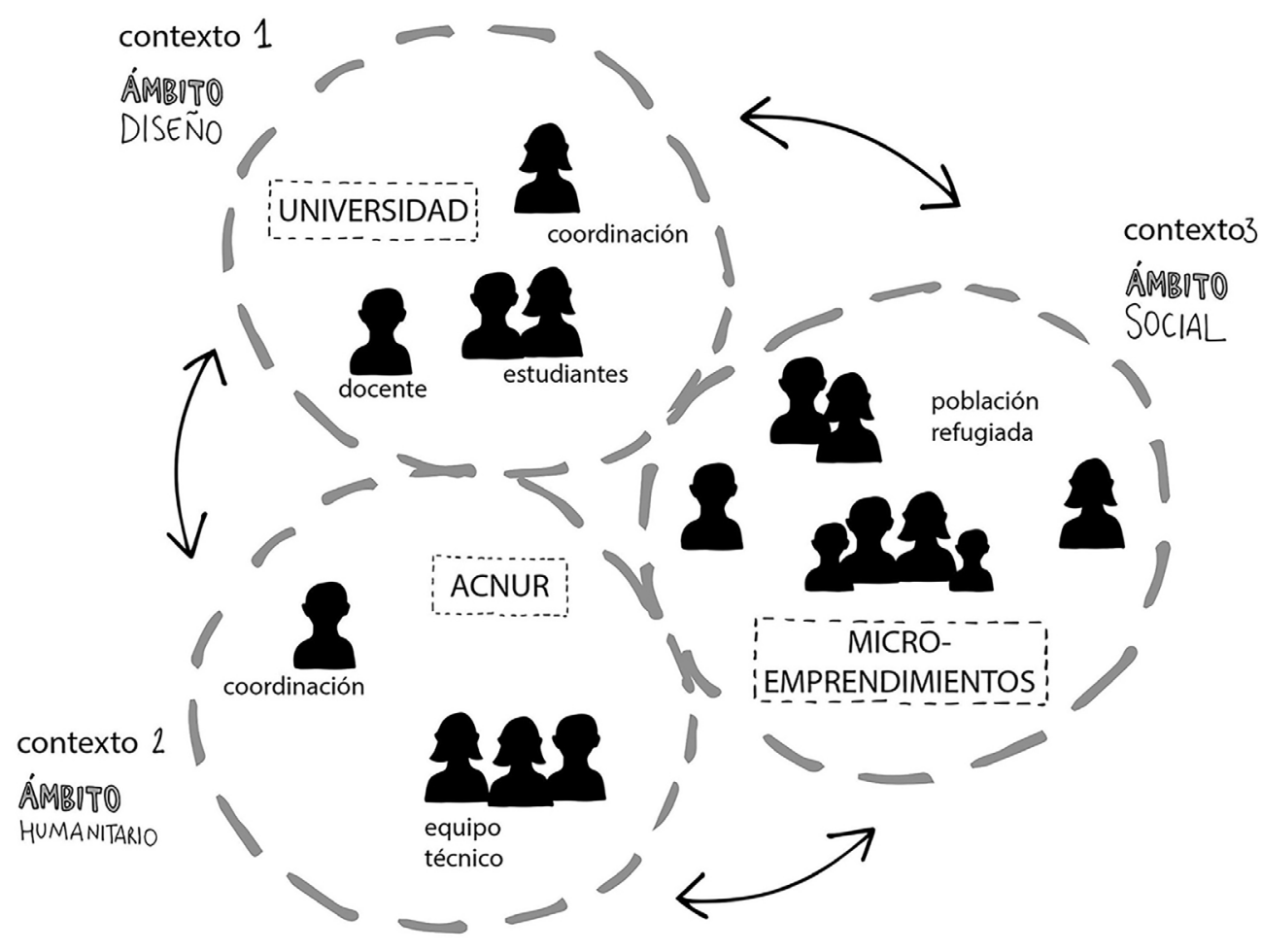

Fig. 4. Mapa de interrelación de contextos implicados.

Para el método de intervención desde la carrera de Diseño Gráfico de la PUCESE se desarrollaron acciones estructuradas en tres etapas: 1) diagnóstico, 2) sesiones de capacitación y 3) intervención de los estudiantes desde las prácticas pre-profesionales. La primera de ellas se corresponde con un diagnóstico de la problemática, realizando sesiones de inducción y sensibilización al tema, tanto para docentes como estudiantes de la escuela. En segundo lugar, se establecen los primeros contactos entre los componentes de la Escuela de Diseño Gráfico, que imparten diferentes sesiones de capacitación con las personas refugiadas, teniendo como ejes centrales la importancia del marketing para el emprendedor y la identidad visual del negocio como elemento imprescindible para el reconocimiento y el asentamiento de su servicio. Se realizaron un total de tres sesiones alrededor de estos ejes. En la última etapa se incorporan los estudiantes que cursan las prácticas pre-profesionales, disciplina para introducirlos en los procesos del mundo laboral. De este modo, tanto los estudiantes como las personas refugiadas coinciden en un proceso de aprendizaje progresivo, el cual se esquematiza en la Figura 5. La estrategia de los estudiantes, recogida del estudio de Margolin y Margolin (2012), consiste en seis fases:

1) Vinculación: el estudiante conoce el programa de ACNUR y de la PUCESE correspondiente al apoyo y seguimiento de emprendimiento de personas refugiadas. Esta inducción es realizada por uno de los técnicos, insistiendo en la sensibilización que el tema conlleva, y la 
responsabilidad que el estudiante asume al trabajar con este colectivo.

2) Valoración: el estudiante visita al emprendedor en su local de negocio, para observar las características del emprendimiento y las expectativas del propietario. Para ello, se realiza una entrevista como primer contacto y un brief de detección de necesidades.

3) Planificación: el estudiante programa su actividad mediante la elaboración de un cronograma de trabajo, visitando con frecuencia según las necesidades al emprendedor para poner en común las propuestas y posibles mejoras.

4) Implementación: con las propuestas gráficas ya consensuadas, cada estudiante lleva a cabo su material para presentar un producto final.

5) Evaluación: el estudiante, como agente protagonista de su propio trabajo, realiza una autoevaluación. El trabajo del estudiante es evaluado por el emprendedor.

6) Conclusión: el estudiante establece unas conclusiones a partir de la experiencia y de su autoevaluación. El equipo de docentes extrae sus conclusiones a través del estudio, entendiendo que resultará un proceso de trabajo positivo si todas las partes expresan su satisfacción.

Esta estrategia, que relaciona a los jóvenes universitarios con la realidad social de la localidad implica que éstos conozcan "su país, su realidad, conozcan su problemática y cuál es su rol dentro de la sociedad desde la profesión de diseñadores gráficos-publicitarios" (Moreno, 2014, p.4).

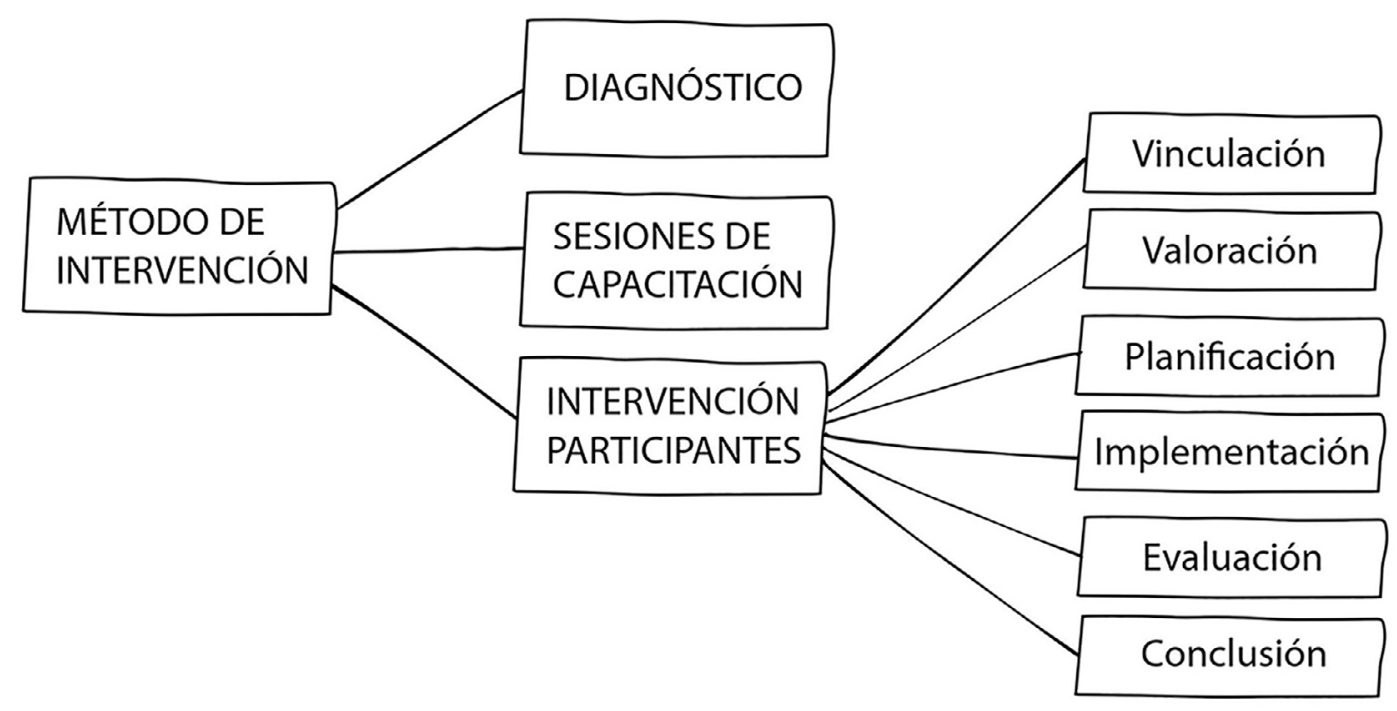

Fig. 5. Método de intervención de la Escuela de Diseño Gráfico-PUCESE, año 2016. 


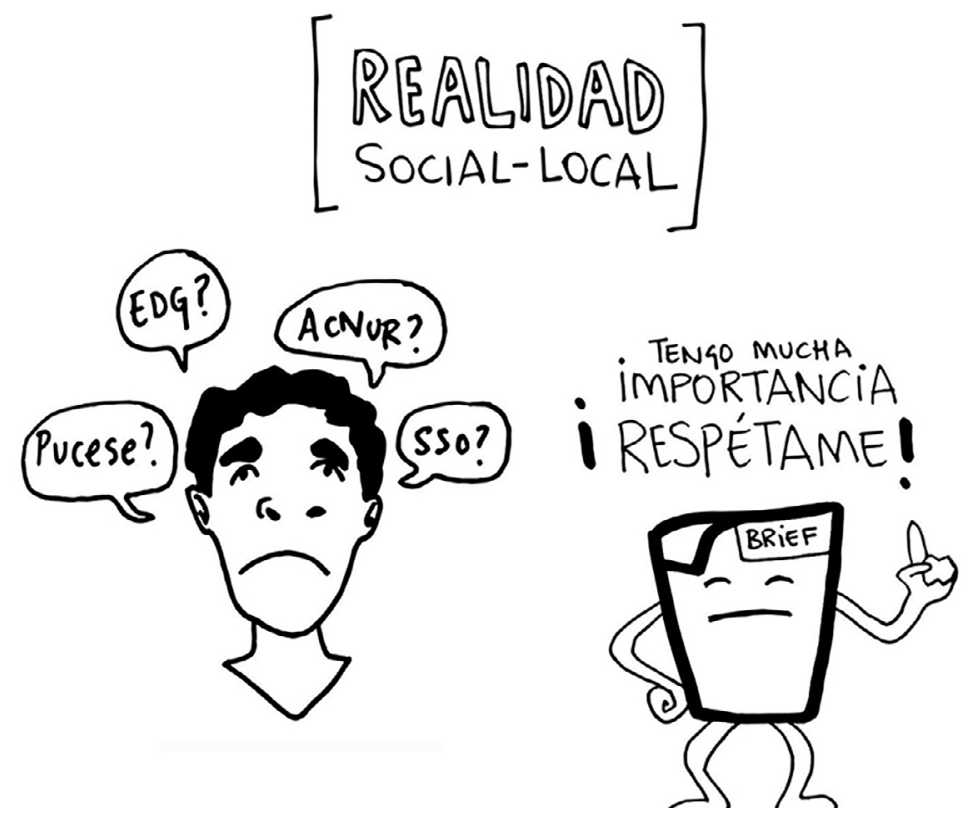

Fig. 6. Ilustraciones empleadas como material didáctico en el proceso de mediación docente.

Una vez que la relación de los estudiantes termina en el proceso de diseño de identidad visual de emprendimientos, se procede a analizar las valoraciones extraídas bajo el parámetro de Satisfacción general del emprendedor, que refleja la percepción de los beneficiarios. Igualmente, las fichas de observación participante durante las sesiones de capacitación evidencian la motivación e implicación de los grupos en el proceso.

\section{Resultados del proceso}

Con lo presentado anteriormente, se procede a exponer los resultados más relevantes para este estudio. Para contextualizar los datos concretos del tema, se hace una revisión retrospectiva de datos proporcionados por la Unidad de Emprendimiento de la PUCESE. Éstos muestran cómo, desde el comienzo del proyecto en el año 2012 hasta el 2016, el equipo reconoce un 78\% de éxito al realizar seguimiento de 91 emprendimientos, de los cuales 71 se encuentran activos y en proceso de avance a diferentes niveles. De los 45 emprendimientos en el periodo 2015-2016, 42 continúan activos, consiguiendo los propósitos de desarrollo, lo que se contempla en un $93 \%$ de éxito. Significa que el plan de seguimiento y apoyo a los emprendimientos de personas refugiadas anualmente incrementa su porcentaje de éxito, generando un elevado impacto micro-empresarial y, por consiguiente, la integración local e independencia económica de la persona refugiada en la ciudad de acogida.

Las evaluaciones de las sesiones de capacitación sobre identidad visual son realizadas tras cada jornada, con el fin de detectar fallos que puedan mejorarse en las siguientes. A partir de ahí, se analizan a través de ítems, estableciendo una escala de 1 para indicar un nivel alto, 2 un nivel medio y 3 un nivel bajo. En la primera sesión se identifica que el nivel de Impacto es bajo, y el más alto es el de Transferencia. La Reacción y el Aprendizaje que ocurre sólo contemplan un nivel medio. La segunda sesión de capacitación contempla igualmente una Reacción y Aprendizaje medios, un nivel de Transferencia de contenidos alto y un Impacto de un nivel medio. En la tercera y última sesión, todos estos niveles aumentan hasta el más alto, exceptuando el de aprendizaje. 
En cuanto a las expectativas de los participantes acerca de la formación, se comprueba que hay un aumento (ítem Reacción) desde las dos primeras sesiones hasta la última de ellas. Según el incremento de conocimientos de cada sesión (ítem Aprendizaje), se muestra cómo la adquisición de conocimientos se mantuvo en un nivel medio en las tres sesiones realizadas. Según el tercer ítem (Transferencia), correspondiente a la aceptación de contenidos, se puede destacar cómo desde el primer momento el grupo de personas refugiadas demuestra entusiasmo por los contenidos presentados en las capacitaciones. Con relación al resultado del trabajo colaborativo y efectos en el entorno del emprendedor (ítem Impacto), se contempla cómo ha avanzado desde un impacto bajo en la primera sesión hasta un nivel alto al finalizar las jornadas. Resumidos estos aspectos en una valoración general de las sesiones, se puede indicar como resultado el incremento de la reacción y buenas sensaciones de los participantes, así como de la aceptación de contenidos y del impacto en sus entornos directos y/o cercanos.

Entre los datos recogidos en las fichas de observación destacan los siguientes aspectos. En relación con las expectativas, las principales demandas giran en torno a la idea de crear marcas que posibiliten la organización y asociación entre los emprendedores que comercializan con productos similares. Entienden como algo necesario el diseño gráfico como medio para posicionar su negocio a nivel local en el mercado, señalando ejemplos de grandes corporaciones que se han convertido en icónicas gracias a sus logotipos y publicidades. En el ambiente distendido y participativo de estas jornadas, además, los emprendedores se muestran con iniciativa a la hora de idear y definir la identidad visual de sus negocios.

De acuerdo con los resultados obtenidos por los cuestionarios, se puede determinar un grado alto de satisfacción. El grupo de personas refugiadas, en su mayoría, califican este proceso como "Muy bueno" (13 de los 26), seguido de 12 de ellos que lo califican como "Excelente". Únicamente uno de ellos determina esta relación como "Buena", y ninguno de los 26 casos señala su descontento (Figura 7). Por ello, se entiende que el trabajo conjunto entre los emprendedores, los docentes y los estudiantes-practicantes de Diseño Gráfico ha sido positivo para el colectivo.

\begin{tabular}{lll}
\hline NIVEL DE SATISFACCIÓN & \\
\hline Excelente & 12 & $46,1 \%$ \\
Muy Bueno & 13 & $50 \%$ \\
Bueno & 1 & $3,8 \%$ \\
Regular & 0 & $0 \%$ \\
Deficiente & 0 & $0 \%$ \\
\hline
\end{tabular}

Fig. 7. Porcentajes de las respuestas valorando la variable Satisfacción general de la persona refugiada emprendedora con el trabajo conjunto con la Escuela de Diseño Gráfico.

Por otro lado, cabe señalar la satisfacción de los estudiantes de diseño gráfico, que, aunque no fueron partícipes de los cuestionarios, al final del proceso elaboraron una evaluación general del proceso. En este sentido, la 
mayoría de ellos expresa su contento con el proceso de prácticas con este colectivo y reconocen que sirve como actividad para profundizar en la realidad y las problemáticas de su región. Asimismo, expresan su orgullo por colaborar en este tipo de proyectos de carácter social desde su posición como futuros profesionales del diseño y la comunicación visual. Por lo que, de manera general, concluyen con un nivel de satisfacción alto. Sin embargo, también indican algunos problemas localizados, siendo los más repetidos el difícil contacto con el emprendedor por un lado (falta de acceso a Internet en algunas zonas) y, por otro, la ausencia en algunos momentos por parte de estos emprendedores (en ocasiones, no tienen horarios de apertura y cierre del local, ya que lo compatibilizan con otras cuestiones de carácter inmediato).

Complementando los resultados expuestos, se incluyen a continuación algunas fotografías y diseños que muestran momentos del proceso. Estos momentos son en primer lugar de trabajo de campo, localizando los emprendimientos con los que trabajar, para poder acordar reuniones y entrevistas con las personas refugiadas. A partir de ahí, la relación entre el estudiante de diseño y el refugiado es autogestionada, pudiendo el estudiante solicitar mediación a sus profesores y las personas refugiadas al equipo PUCESE-ACNUR. La recogida de documentación de estos encuentros se realiza respetando en todo momento el derecho de anonimato de la población en cuanto a difusión y privacidad de imagen debido a su situación.

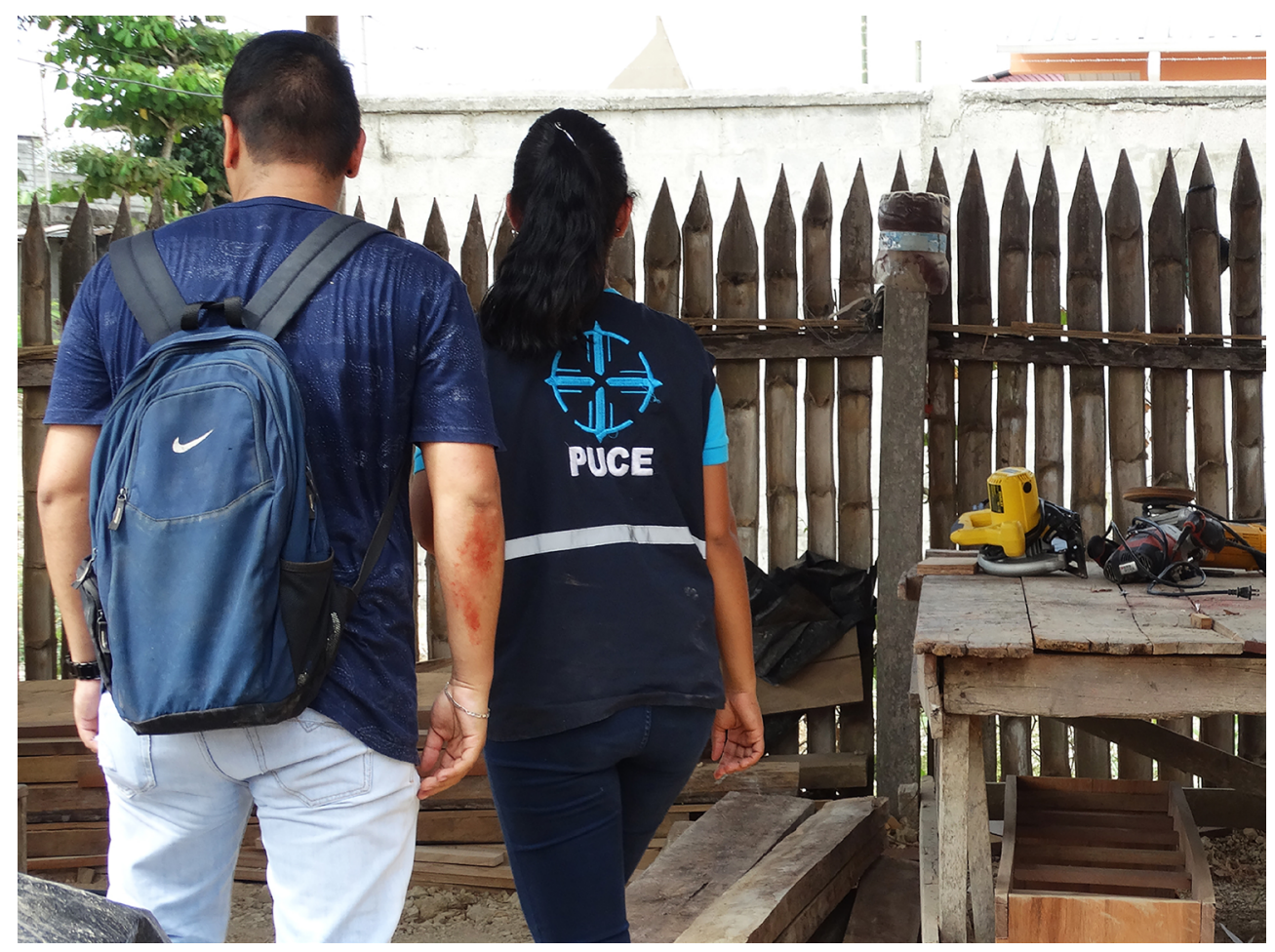

Fig. 8. Visita de equipo a emprendimiento de carpintería. Fotografía: Nuria Rey.

Tras el consenso entre el estudiante y el refugiado hacia la concreción de una identidad visual para el emprendimiento, el estudiante-practicante comienza el trabajo creativo mediante bocetaje manual y digital, avanzando en las pruebas con el aporte de los beneficiarios y los docentes. A continuación, se incluyen algunas imágenes sobre este proceso de diseño, rediseño o adaptación de marca al contexto de los emprendimientos. 

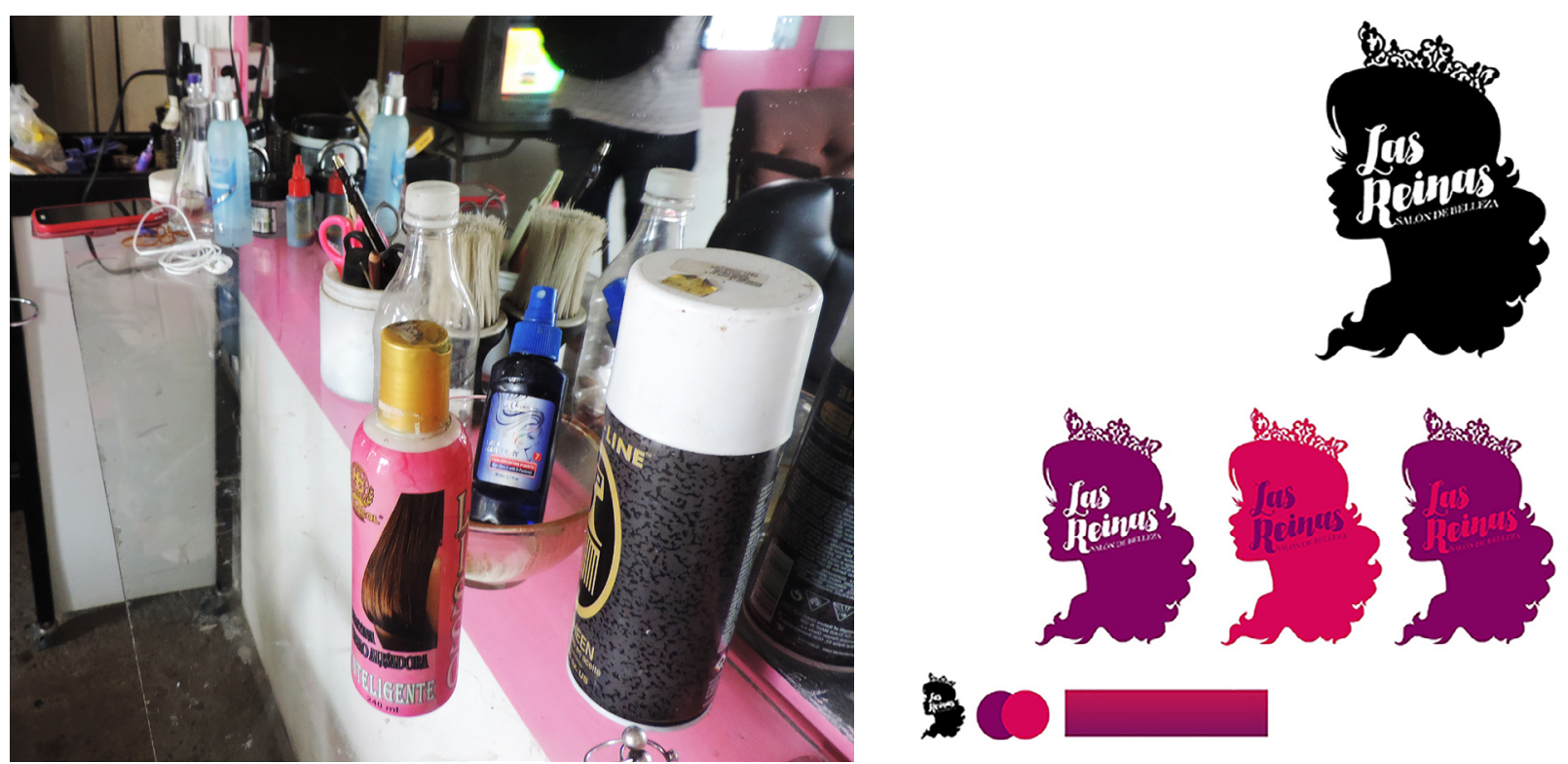

Fig. 9 y 10. Emprendimientos de estética y su posible transformación a marca. Fotografía por: Alex Quinde. Diseñador:Wagner Mite.

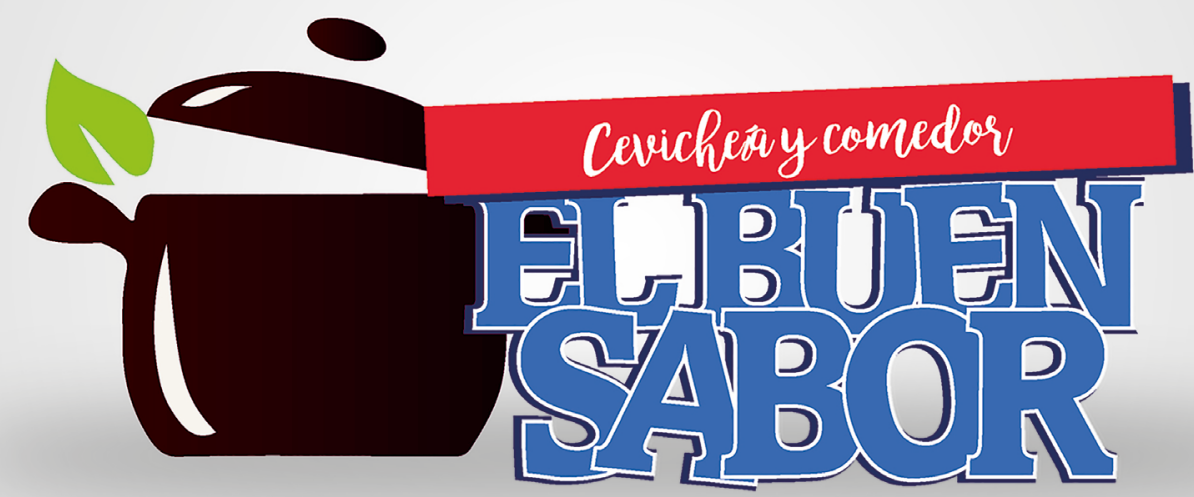

Fig. 11. Ejemplo de rediseño de marca. Diseñador: Diego Hurtado. 

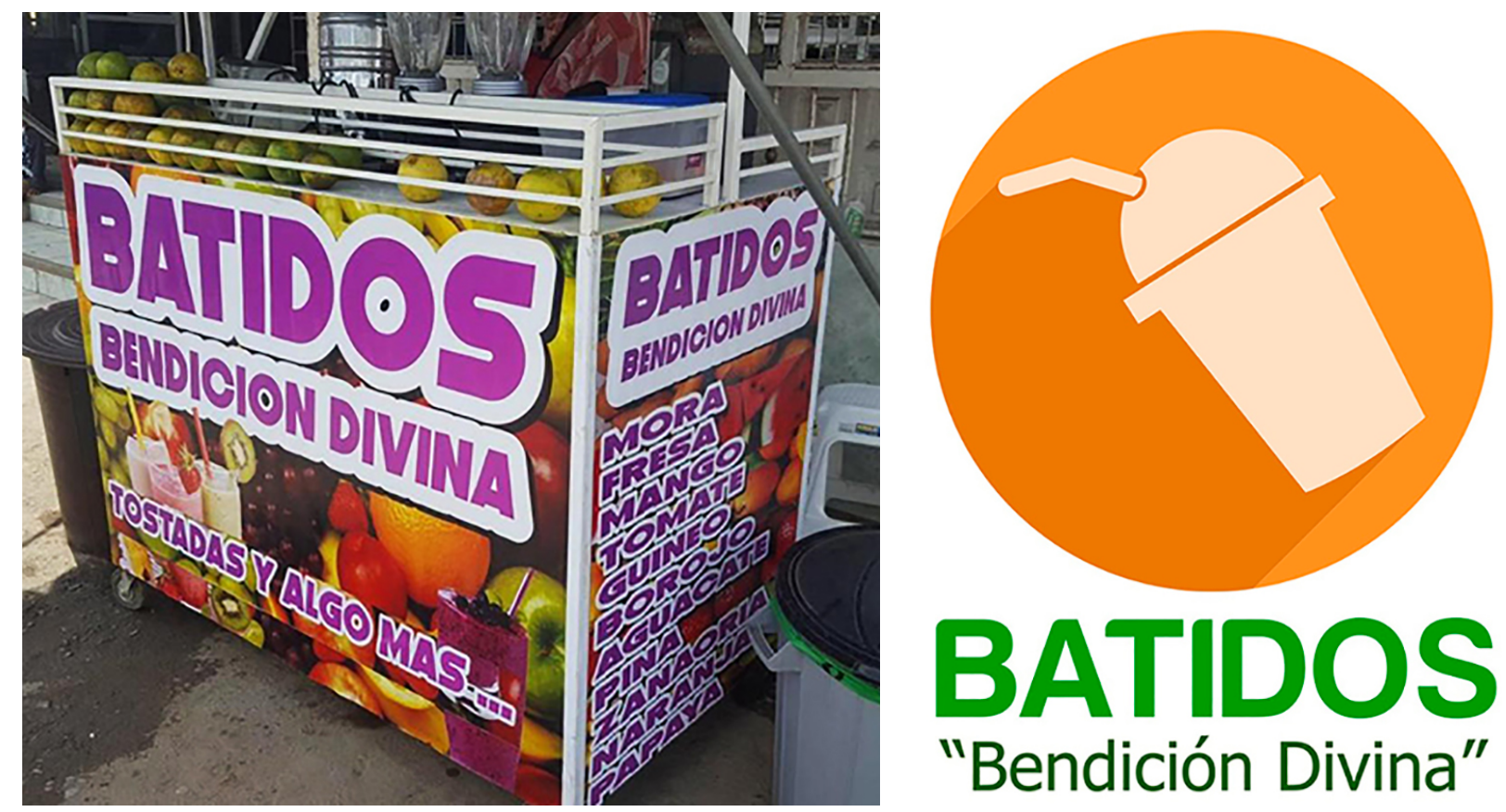

Fig. 12 y 13. Rediseño de emprendimiento. Diseñador y fotografía: Abraham Cedeño.

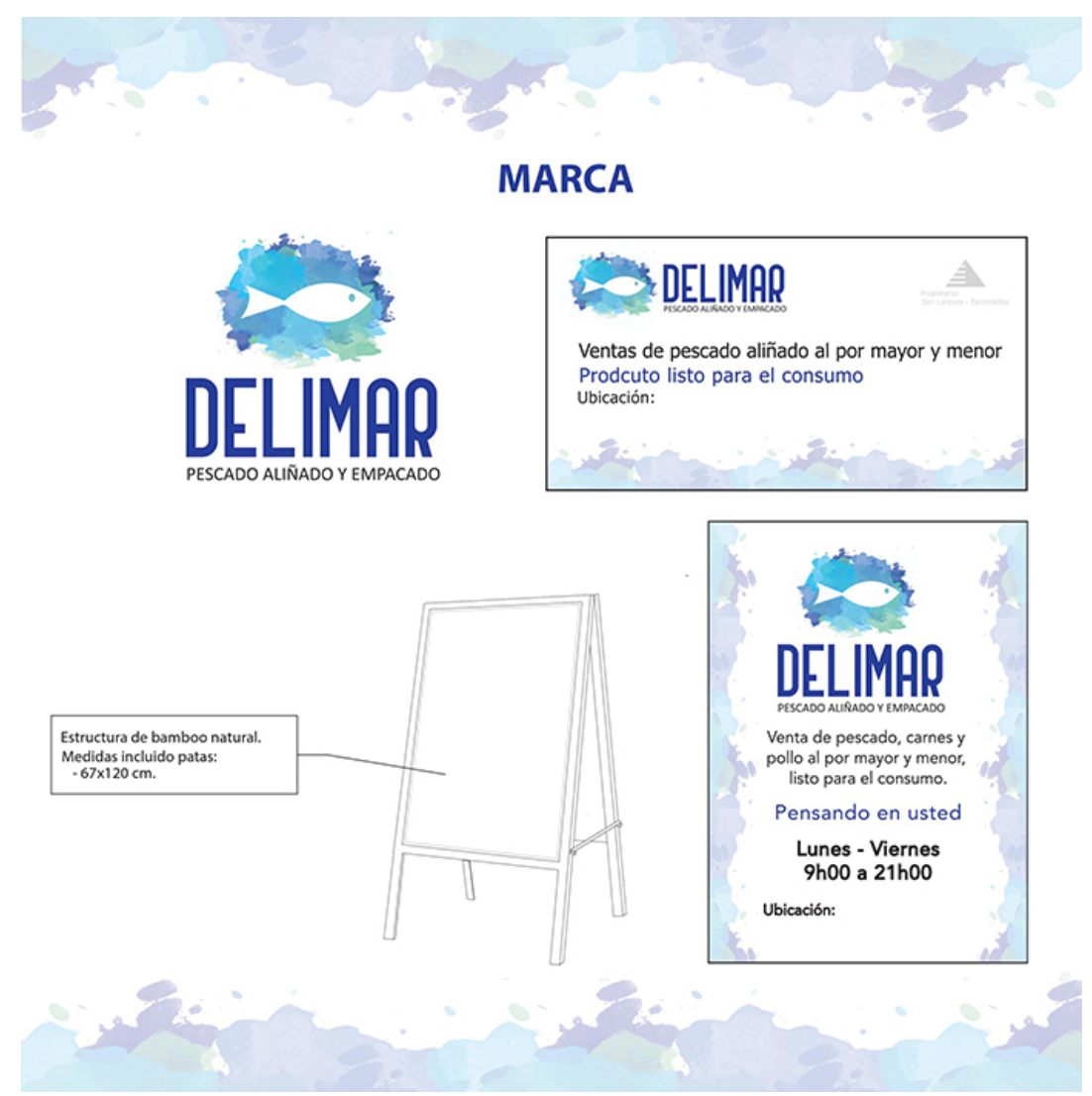

Fig.14. Ejemplo de productos de identidad visual. Diseñadora: Cristina Mieles 


\section{Discusión: ¿es apropiada la incorporación de diseñadores en el proceso de integración social?}

El aporte del diseñador, según las necesidades de implementar propuestas sociales, sería el de integrar nuevos modos de producción siendo más colaborativos, con el fin de utilizar los lenguajes y construcciones gráficas a favor de las demandas de una comunidad concreta. En este proceso "las identidades de los grupos sociales se construyen cada vez menos sobre su repertorio de símbolos locales" (Melenje, 2014, p.167), por lo que se entremezclan las tradiciones visuales concretas con las del mundo globalizado, permitiendo hibridaciones entre lo local y lo general.

Los diseñadores juegan un papel decisivo al poner en escena discursos y artefactos visuales que en muchos casos se transforman en potentes íconos globales, que adquieren su carácter local a través de los medios de comunicación, los procesos de hibridación y los imaginarios e identidades locales. Estas relaciones producen imágenes que se alimentan tanto de lo local como de lo global (Melenje, 2014, p.167).

El trabajo del diseñador gráfico social, por lo tanto, deambula entre la producción tradicional de la identidad visual y los procesos socioculturales en los que se ve envuelto el colectivo participante hasta llegar a una meta común. De este modo, se genera motivación entre los diferentes actores para convertirse en gestores del desarrollo a partir de la representación de la cultura (Henao \& Suárez, 2014). Esta imagen generada de manera colectiva debe reflejar la personalidad, distinguiéndose de las demás y situándola dentro del sector en el que se desarrolle (Ramírez \& Gochicoa, 2010). Por lo tanto, el primer objetivo del diseñador gráfico que se implica en procesos de emprendimientos sociales es el de colaborar y empoderar a la persona refugiada, compartiendo y proporcionando herramientas referentes a la identidad visual que debe representar tanto al propietario como a la región de acogida.

Esto se convierte en un aspecto fundamental cuando la realidad muestra fenómenos como la discriminación hacia la persona refugiada en Esmeraldas. El entorno de acogida percibe al emprendedor refugiado como un intruso, generando ideas negativas preconcebidas sobre este segmento de la población. Estos datos se localizan en el informe de ACNUR del año 2013, en el que se insiste que, con el aumento de la inseguridad, la persona local esmeraldeña comienza a rechazar al refugiado colombiano desde la sospecha.

La buena construcción de la imagen de un negocio tiene un efecto directo sobre el sujeto, y le permite verse como parte de algo, por lo que el individuo aportará al proceso de integración y al desarrollo comercial local, ya que, si el emprendimiento consigue un asentamiento y una expansión sólida, se convierte en un potencial generador de empleo. Por ello, se puede reflejar en este punto que el diseñador se convierte en productor de imaginarios culturales, en un "interlocutor cultural" (Melenje, 2014, p.164).

Según las fases del trabajo de ACNUR, la integración llega cuando la persona refugiada se convierte en un agente autónomo, capaz de participar en la vida cotidiana del país o ciudad de acogida, sin perder sus particularidades y sus raíces. Para ello, además de la intervención de asociaciones y ONG's, se insiste en establecer diferentes convenios con otras autoridades, con el fin de desarrollar distintas capacitaciones que lleven finalmente a esa autonomía. En este caso, el trabajo del diseñador desde la universidad, siendo el agente de colaboración la PUCESE, recoge esa recomendación de ACNUR para dotar de habilidades al colectivo de refugiados que les permitan desenvolverse a nivel promocional. Por otro lado, las autoridades 
locales, tanto a nivel público como privado, identifican mejor el carácter profesional de un negocio cuando éste tiene definidas sus características gráficas y estéticas (esto es, uniforme, marca, logotipo o ícono identitario, etiquetado propio...), generando impacto tanto en el negocio del emprendedor como en la población en general. Igualmente, los materiales de los que el equipo de apoyo y seguimiento al refugiado pueda disponer (material de difusión de proyectos, vídeos promocionales, material gráfico de concienciación...) son herramientas clave para la integración de la persona refugiada. En este sentido, el diseñador gráfico social puede colaborar tanto con el colectivo de emprendedores refugiados directamente como con la entidad de acción social que desarrolle sus programas de ayuda.

Es aquí donde nace la pregunta que puede llevar a un replanteamiento dentro de los programas para la integración, y es si estos planes de seguimiento y atención a la situación laboral del refugiado deben incluir un equipo de diseñadores. En este tipo de casos, que el diseñador sea un actor que medie entre asociaciones, universidad y beneficiarios, se aleja de la necesidad de que el "trabajo social con refugiados estará siempre vinculado y condicionado por los aspectos legales en materia de extranjería y, más concretamente, en el ámbito de protección a los refugiados" (Vega, 1996, p.156). Quizás por esa prioridad se conforman equipos de intervención social donde el diseñador no tiene cabida. Atendiendo una vez más a ACNUR, para que la integración ocurra se deben desarrollar situaciones para que las personas refugiadas dispongan de "una integración legal, económica, social, de vivienda, de seguridad, educativa, cultural y laboral” (2013, p.8). Si, como se ha expuesto en la dimensión teórica, se entiende al diseñador como operador cultural, éste será capaz de potenciar las relaciones de la visualidad con la sociedad contemporánea. Esta relación se encuentra en las reflexiones de Ledesma (2003, p.36) cuando recalca que "el diseño no es neutro" o las de Frascara (1997, p.23) al comprender al diseñador como figura responsable de "transformar una realidad existente por una realidad deseada". En la misma línea escribe Paris-Clavel (1997) cuando explica que el rol social del diseñador es el de involucrarse en la sociedad utilizando sus recursos de expresión para el conocimiento de las problemáticas sociales. Según las referencias desde la cultura del diseño, y del diseño como campo de intervención en la sociedad, estaría justificada su aportación en este tipo de procesos.

Entonces, para una inclusión social, cultural y laboral sí parece apropiado que en la fase de integración colabore un diseñador o equipo diseñador desde diferentes actividades, pudiendo desarrollar procesos de identidad visual, capacitaciones de marketing y cultura visual que empoderen a los emprendedores para situar su negocio dentro del desarrollo de la región de acogida, o realizando distintos materiales de concientización de la problemática concreta para su difusión pública. De esta manera, la respuesta a la cuestión que impulsa esta discusión parece afirmativa, entendiendo la figura del diseñador gráfico como un profesional capaz de participar en sintonía con otras áreas socioculturales o políticas desde el carácter colaborativo.

\section{Conclusiones}

Los objetivos del estudio han sido cumplidos de la manera en que se expone a continuación. A la hora de establecer algunas conclusiones sobre ellos, se determina que la participación de diseñadores en procesos de integración de personas refugiadas otorga ventaja en el asentamiento y difusión del emprendimiento en la región de acogida. Para ello, es imprescindible que el diseñador actúe desde los parámetros del diseño social, siendo partícipe de la comunidad en la que se da esta situación o capacitándose para comprender el 
contexto en el que trabaja. Debe entenderse, pues, como un agente sociocultural que puede contribuir con sus capacidades al beneficio del colectivo. Se debe señalar, además, el carácter heterogéneo del proceso al trabajar con el colectivo refugiado, ya que es posible que surjan ciertos obstáculos como que el emprendedor no se encuentre en su lugar de negocio para las reuniones programadas.

Como se expuso anteriormente, el marco de acción del que parte esta experiencia es favorable, situando el programa de apoyo a los emprendimientos en niveles de éxito cada vez mayores desde 2012. Atendiendo a los resultados obtenidos, las fichas de observación sustentan el incremento de expectativas por parte de los participantes. El aprendizaje de contenidos ha sido de un nivel medio en todas ellas, mientras que el nivel de aceptación de estos en todas las jornadas ha sido alto. El impacto de las capacitaciones en la iniciativa del emprendedor ha sido progresivo, siendo bajo en un primer momento para convertirse en alto al final, mostrando el grupo su capacidad para asociarse de manera colaborativa y comprender que el soporte de una identidad visual sólida es un elemento beneficioso para sus emprendimientos. Según esto, se puede indicar que los contenidos de las capacitaciones pasan a un segundo plano, ya que el grupo de refugiados prioriza las relaciones, los intercambios de opinión y el debate. Por ello, la recomendación que se hace aquí es la de proponer relaciones y espacios dinámicos, participativos y flexibles, alejándose de situaciones de educación tradicional. Otra aportación para estas conclusiones la otorgan los resultados extraídos de los cuestionarios, que indican que los refugiados participantes en el proceso gráfico de sus emprendimientos tienen una valoración positiva a nivel general, tanto de los resultados como de las relaciones con los docentes y estudiantes-practicantes de diseño.

Por todo ello, se concluye que la estrategia llevada a cabo con los participantes refugiados ha funcionado y ha tenido un impacto positivo tanto para su integración a través de la identidad gráfica de sus negocios como para los colaboradores diseñadores.

Este resultado final no puede comprenderse sin tener en cuenta la constancia e implicación por parte de todas las personas que intervienen en la acción, ya que si no existiera ese compromiso continuo puede que las conclusiones en una experiencia similar fueran distintas.

Extrapolando esta experiencia, puede establecerse como conclusión general que el desarrollo de procesos de diseño social enriquece la respuesta y acción frente a distintas demandas de mejora social, afectando a las personas implicadas, incluido el propio diseñador, que puede encontrar motivaciones más sensibles para su labor.

Una de las aplicaciones futuras que derivan de esta experiencia es la de estimar el impacto a nivel de conjunto social y económico de los emprendimientos. De esa manera, podrían estudiarse las consecuencias a escala mayor de este proceso. Por otro lado, sería enriquecedor determinar en qué medida el colectivo refugiado ha seguido contando con procesos de diseño gráfico aplicados a su negocio a largo plazo, comprobando si esta experiencia ha supuesto un punto de inflexión en la confianza de los emprendedores hacia procesos comunitarios de identidad visual. 


\section{Bibliografía}

AICHER, O. El mundo como proyecto, México, Gustavo Gili, 1994.

ACNUR, ¿Quién es un refugiado? Guía de preguntas, 2016 <http://www.acnur.org/a-quien-ayuda/refugiados/ quien-es-un-refugiado/> (20.11.2017).

ACNUR, ACNUR en Ecuador, 2014 <http://www.acnur.org/t3/fileadmin/Documentos/RefugiadosAmericas/ Ecuador/2014/ACNUR_Ecuador_2014_Frontera_ES_Abril_v2.pdf?view=1> (15.12.2017).

ACNUR, Investigación sobre la integración de los refugiados en Esmeraldas. Informe final, 2013 <http://www.cpccs.gob.ec/docs/niceditUploads/tempo/1408739831Informe\%20final\%20sobre\%20 integraci\%C3\%B3n\%20de\%20los\%20refugiados\%20\%20en\%20Esmeraldas.pdf> (10.12.2017).

BERNARD, R. \& MORALES, J. M. "El diseño social en la mejora de la prestación de Servicios Sociales para la Inclusión Social” en Documentación social, n¹65, 2012, Madrid, pp. 207-223.

BONSIEPE, G. Del objeto a la interfase. Mutaciones del diseño. Buenos Aires, Ediciones Infinito, 1999.

BROWN, T. "Design Thinking”, en Harvard Business Magazine, $2008<\mathrm{https}: / / \mathrm{hbr}$.org/2008/06/designthinking $>$ (14.04.2018).

CÁCERES, L. E. Diseño social, parto humanizado, Doulas. Proyecto Kuyana, red de Doulas Ecuador, Savia Materna, Quito, Universidad San Francisco de Quito, 2015.

COSTA, J. "Diseño de Comunicación Visual: el nuevo paradigma" en Gráfica. Documentos de diseño gráfico, vol. 2, n4, 2014, Barcelona, pp.87-107.

DEL VALLE, M. "Cartografía del diseño social: aproximaciones conceptuales” en Anales del Instituto de Arte Americano e Investigaciones Estéticas Mario J. Buschiazzo, vol. 43, n¹, 2014, Buenos Aires, pp. 97-106.

EQUITAS - CENTRO INTERNACIONAL PARA LA EDUCACIÓN EN DERECHOS HUMANOS Y OFICINA DEL ALTO COMISIONADOS DE LAS NACIONES UNIDAS PARA LOS DERECHOS HUMANOS. "Cómo evaluar las actividades de capacitación en derechos humanos. Manual para educadores" en Serie de capacitación profesional, n¹8, 2010, Ginebra.

FRASCARA, J. Diseño gráfico para la gente, Buenos Aires, Gustavo Gili, 1997.

GÓMEZ, Y. N. “Diseño, responsabilidad social y desarrollo local” en Creatividad y Sociedad, n²2, 2014, Madrid, pp. 1-22.

GUBER, R. "La observación participante como sistema de contextualización de los métodos etnográficos: la investigación de campo de Esther Hermitt en los Altos de Chiapas, 1960-1961" en Revista Latinoamericana de Metodología de las Ciencias Sociales, vol. 1, n², 2013, Buenos Aires, pp.60-90.

HENAO, J. L. \& SUÁREZ, A. "Diseño social como estrategia para el desarrollo de la sociedad" en Grafías Disciplinares de UCP, n²5, 2014, Pereira, pp. 143-149.

HERNÁNDEZ, R., FERNÁNDEZ, C. \& BAPTISTA, P. Metodología de la investigación, México, Mc Graw Hill Education, 2014.

JARAMILLO, A. R. El diseño social en la calidad de vida de los moradores de la urbanización Julio Ordóñez Espinosa de la ciudad de Loja, Loja, Universidad Técnica Particular de Loja, 2011. 
LEDESMA, M. El diseño gráfico. Una voz pública (de la comunicación visual en la era del individualismo), Buenos Aires, Argonauta, 2003.

LEDESMA, M. Comunicación para diseñadores, Buenos Aires, CEADIG, 2009.

LOEWY, G. Fragmentos de: e-valuation para el diseño, e-conomía, e-cología y é-tica, Dossier Interfase, Buenos Aires, CMD, 2002.

MARGOLIN, V. \& MARGOLIN, S. “Un modelo social de diseño: cuestiones de práctica e investigación" en KEPES, vol. 9, $\mathrm{n}^{\circ} 8,2012$, Caldas, pp. 61-71.

MELENJE, A. "Itinerario: Diseño Gráfico, Cultura Visual e identidades locales" en Cuadernos del Centro de Estudios de Diseño y Comunicación, vol. 14, n47, 2014, Buenos Aires, pp. 163-180.

MENDIA, I. Desplazados internos. Diccionario de Acción Humanitaria y Cooperación al Desarrollo <http:// www.dicc.hegoa.ehu.es/listar/mostrar/74> (10.02.2018).

MORENO, C. "El diseño gráfico y su responsabilidad social" en Creatividad y Sociedad, n²2, 2014, Madrid, p.1-15.

NOWOTNY, H. The potencial of the transdisciplinarity, 2006 <http://www.helga-nowotny.eu/texts.php> (13.04.2018).

PAPANEK, V. Design for human scale, Nueva York, Van Nostrand Reinhold, 1983.

PAPANEK, V. Design for the real world: human ecology and social change, Nueva York, Pantheon Books, 1971.

PARIS-CLAVEL, G. "El diseño cobra sentido realmente si persigue un objetivo social. Con su capacidad de expresión simbólica puede fomentar el conocimiento y cuestionamiento de los problemas que aquejan a nuestra sociedad", en Revista Tipográfica, año XI, 33, 1997.

PELTA, R. "Diseño y activismo. Un poco de historia", en Monográfico.org, revista temática de diseño, 2002 $<$ http://www.monografica.org/02/Art\%C3\%ADculo/2909> (14.04.2018).

RAMÍREZ, J. I. \& GOCHICOA, E. F. "Imagen corporativa: ventaja competitiva para las organizaciones PYME" en Ciencia Administrativa, n 1 , 2010, Veracruz, pp. 1-8.

VEGA, M. J. "Fases de la intervención social con refugiados" en Alternativas. Cuaderno de Trabajo Social, no . 4, 1996, Alicante. 